\title{
STUDI POWER QUALITY \\ DI BALAI LATIHAN PENDIDIKAN TEKNIK (BLPT) YOGYAKARTA
}

\author{
Alex Sandria Jaya Wardhana ${ }^{1}$, Ismu Wijayanto ${ }^{2}$ \\ ${ }^{1}$ Jurusan Pendidikan Teknik Elektro FT UNY, ${ }^{2}$ Balai Latihan Pendidikan Teknik Yogyakarta \\ Email: alexwardhana@uny.ac.id, ismusama@gmail.com
}

\begin{abstract}
The quality of electrical power is a common condition that describes the characteristics of the parameters of electrical quantities. This study aims to determine the power quality profile that includes current, voltage, active power, reactive power, apparent power, frequency, harmonic current, and voltage harmonics. Power quality profile is done by measuring for 24 hours to determine the characteristic qualities of the object of research in Balai Latihan Pendidikan Teknik (BLPT) Yogyakarta. Measurements were taken at each of output transformer $250 \mathrm{kVA}$ at BLPT Yogyakarta. Based on the measurement results, the total peak load for loading in BLPT Yogyakarta is 129.242,45 VA or equal to 51.70\% of the installed transformer capacity. The most prominent conditions of measurement results are any indication of the current flow in the neutral wire is high enough, ie 103,05 amperes, which will impact on the value of the energy loss in the neutral wire and losses in the transformer.
\end{abstract}

Keywords: power quality, profile, measurement

\begin{abstract}
ABSTRAK
Kualitas daya listrik (power quality) merupakan syarat umum yang menggambarkan karakteristik parameter-parameter besaran listrik. Penelitian ini bertujuan untuk mengetahui profil kualitas daya yang meliputi arus, tegangan, daya aktif, daya reaktif, daya semu, frekuensi, harmonik arus dan harmonik tegangan. Profil kualitas daya dilakukan dengan melakukan pengukuran selama 24 jam untuk mengetahui karakteritik kualitas daya dengan objek penelitian pada gedung Balai Latihan Pendidikan Teknik (BLPT) Yogyakarta. Pengukuran dilakukan pada output trafo dengan kapasitas $250 \mathrm{kVA}$ yang ada di BLPT Yogyakarta. Berdasarkan hasil pengukuran, beban puncak total untuk pembebanan di BLPT Yogyakarta adalah 129.242,45 VA atau sebesar $51,70 \%$ dari kapasitas trafo yang terpasang. Kondisi yang paling menonjol dari hasil pengukuran adalah adanya indikasi aliran arus di kawat netral yang cukup tinggi, yaitu 103,05 ampere di mana nilai tersebut akan berdampak pada kerugian energi pada saluran netral maupun rugi-rugi pada transformator.
\end{abstract}

Kata kunci: kualitas daya listrik, profil, pengukuran.

\section{PENDAHULUAN}

Energi merupakan salah satu faktor yang sangat diperlukan untuk pembangunan berkelanjutan dan pertumbuhan ekonomi. Jumlah energi listrik terjual pada tahun 2018 sebesar 234.617,88 GWh meningkat 5,15\% dibandingkan tahun sebelumnya. Sektor pelanggan industri mengkonsumsi 32,80\%, rumah tangga $41,70 \%$ dan sektor lain yaitu social, gedung pemerintah dan penerangan jalan umum sebesar $6,74 \%$. Berdasarkan data diatas dua sektor paling dominan yaitu sektor rumah tangga dan sektor industri yang terus tumbuh dari tahun ke tahun. Jumlah pelanggan pada akhir tahun 2018 sebesar 71.917.397 pelanggan meningkat 5,65\% dari akhir tahun 2017 (PT PLN Persero, 2018).

Menurut Dugan, R.C dkk (1996), kualitas daya listrik (power quality) adalah syarat umum yang menggambarkan karakteristik parameter catuan seperti arus, tegangan, frekuensi, serta menggambarkan dampak negatif dari gangguan listrik, seperti deviasi frekuensi, variasi tegangan sumber, tegangan transien, harmonik dan sebagainya. Kualitas daya dan faktor ekonomis saling berhubungan. Faktor ekonomis sangat tergantung kepada pemilihan peralatan yang akan dioperasikan di pabrik dan pensuplaian pada peralatan pabrik yang menjadi 
beban listrik. Aanya kualitas daya yang baik maka faktor ekonomis dapat ditekan seminimal mungkin. Stamenić et al. (2012) menyatakan bahwa dengan mengetahui profil kualitas daya listrik dengan melakukan pengukuran maupun audit energi akan didapatkan potensi anomali penggunaan energi dan menentukan peluang konservasi energi yang bisa dilakukan.

Suatu bangunan gedung dikatakan memiliki kualitas daya yang baik apabila tegangan, arus, frekuensi dan faktor dayanya konstan. Suatu bangunan baik gedung sebagai tempat aktififitas yang membutuhkan peralatan listrik maupun industry yang didalamnya memiliki proses produksi selalu membutuhkan dua hal berikut untuk mendukung proses aktifitasnya, yaitu: 1) suplai listrik yang kontinyu. Hal ini untuk menjaga suplai listrik tetap kontinyu, maka digunakan sumber listrik cadangan yaitu genset (generator-set), khususnya untuk beban-beban penting; dan 2) kualitas daya listrik yang baik. Kualitas daya listrik yang baik sangat diperlukan karena banyak peralatan-peralatan elektronik yang dipergunakan.

\section{Profil BLPT Yogyakarta}

BLPT Yogyakarta (2015) diresmikan oleh Menteri Pendidikan dan Kebudayaan Republik Indonesia pada hari Selasa, 31 Maret 1981 beserta 3 (tiga) BLPT lainnya yaitu BLPT Padang, BLPT Palembang dan BLPT Semarang. Dengan demikian di Indonesia terdapat 9 (sembilan) BLPT di mana 5 BLPT sudah diresmikan sebelumnya yaitu: BLPT Jakarta, BLPT Bandung, BLPT Surabaya, BLPT Medan, dan BLPT Ujung Pandang .

Sejak diberlakukannya Otonomi Daerah Tahun 2001, BLPT diserahkan kepada Pemerintah Provinsi Daerah Istimewa Yogyakarta sebagai Unit Pelaksana Teknis Daerah (UPTD) di bawah Dinas Pendidikan, Pemuda dan Olahraga Provinsi Daerah Istimewa Yogyakarta. Sejak saat itu pula BLPT dikembangkan tugas pokok dan fungsinya untuk melayani pendidikan dan pelatihan bagi
Sekolah Menengah Kejuruan (SMK) Negeri/Swasta, Perguruan Tinggi Negeri/Swasta, Instansi/Lembaga, Dunia Usaha/Dunia Industri, dan masyarakat umum dari DIY maupun luar DIY.

BLPT Yogyakarta memiliki 4 program diklat yang diselenggarakan yaitu, otomotif, mesin, elektro, dan informatika, serta sipil dan futniture, di mana sumber listrik yang dimiliki (utama) diperoleh dari PLN dan Genset sebagai sumber energi listrik cadangan. Kapasitas daya terpasang pada trafo yang dimiliki oleh BLPT DIY yaitu sebesar $250 \mathrm{kVA}$.

\section{METODE}

Alat atau instrumen dalam penelitian ini berupa power quality analyzer (analyst $\mathrm{A} 3 \mathrm{Q}$ ) untuk pengukuran sumber listrik 3 fase. Instrumen alat ukur digunakan untuk mengukur data-data yang terkait dengan kualitas daya (digunakan untuk pengukuran power quality) maupun pengukuran lain yang dibutuhkan, sedangkan perangkat dokumentasi digunakan untuk mengambil gambar atau kejadiankajadian yang mendukung dalam mengungkap data tingkat konsumsi energi.

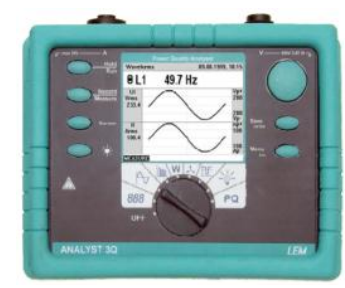

Gambar 1. Alat Ukur Power Quality Analyzer

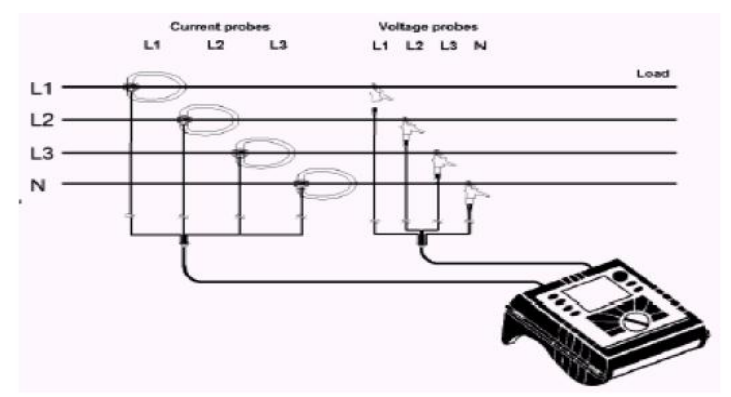

Gambar 1. Pemasangan Alat Power Quality

Titik pengukuran difokuskan pada 
incoming MDP utama dari trafo $250 \mathrm{kVA}$. Hal ini bertujuan untuk mendapatkan data pengukuran secara total terhadap beban tersambung. Hasil pengukuran yang direkam antara lain;

a) Data arus fase dan netral $\left(\mathrm{I}_{\mathrm{R}}, \mathrm{I}_{\mathrm{S}}, \mathrm{I}_{\mathrm{T}}\right)\left(\mathrm{I}_{\mathrm{N}}\right)$

b) Data tegangan fase-netral $\left(\mathrm{V}_{\mathrm{R}-\mathrm{N}}, \mathrm{V}_{\mathrm{S}-\mathrm{N}}, \mathrm{V}_{\mathrm{T}-\mathrm{N}}\right)$ dan tegangan fase-fase $\left(\mathrm{V}_{\mathrm{R}-\mathrm{S}}, \mathrm{V}_{\mathrm{S}-\mathrm{T}}, \mathrm{V}_{\mathrm{T}-\mathrm{R}}\right)$

c) Data Frekuensi

d) Data Power Factor

e) Total Harmonic Distortion Voltage (THDV)

f) Total Harmonic Distortion Current (THDI)

g) Data Daya Listrik (daya semu, daya nyata, daya reaktif)

Data yang sudah didapatkan selanjutnya dianalisis kemudian dibandingkan dengan standart kelistrikan yang berlaku.

\section{HASIL DAN PEMBAHASAN}

Karakteristik beban diperlukan agar sistem tegangan dan pengaruh thermis dari pembebanan dapat dianalisis dengan baik.
Analisis tersebut termasuk dalam menentukan keadaan awal yang akan diproyeksikan dalam perencanaan selanjutnya. Penentuan karakteristik beban listrik suatu transformator sengat penting guna mengevaluasi pembebanan transformator tersebut, ataupun dalam merencanakan sebuah transformator yang baru.

Karakteristik beban ini sangat memegang peranan penting dalam memilih kapasitas transformator secara tepat dan ekonomis. Di lain pihak sangat penting artinya dalam menentukan rating peralatan pemutus rangkaian, analisis rugi-rugi dan menentukan kapasitas pembebanan dan cadangan yang tersedia dan suatu transformator. Karakteristik beban listrik suatu transformator sangat tergantung pada jenis beban yang dilayaninya. Hal ini akan jelas terlihat dan hasil pencatatan kurva beban selama interval waktu tertentu.

Tabel 1. Hasil Pengukuran Power Quality di BLPT Yogyakarta

\begin{tabular}{clcccc}
\hline No. & \multicolumn{1}{c}{ Parameter } & Fase R & Fase S & Fase T & Netral \\
\hline 1 & $\begin{array}{l}\text { Arus kondisi beban rata-rata } \\
\text { (ampere) }\end{array}$ & 73,73 & 73,27 & 105,77 & 32,36 \\
2 & $\begin{array}{l}\text { Arus kondisi beban maksimal } \\
\text { (ampere) }\end{array}$ & 177,83 & 203,40 & 227,37 & 103,05 \\
3 & Tegangan (V), Volt & 216,74 & 218,35 & 213,95 & - \\
4 & Daya Aktif (P), Watt & $13.754,76$ & $14.905,23$ & $21.331,35$ & - \\
5 & Daya semu (S), VA & $15.927,55$ & $15.913,21$ & $22.561,11$ & - \\
6 & Daya Reaktif (Q), Var & $7.675,17$ & $4.734,17$ & $6.096,47$ & - \\
7 & Faktor Daya (PF) & 0,86 & 0,95 & 0,96 & - \\
8 & Frekuensi (Hz) & \multicolumn{2}{c}{49,85} & & \\
9 & Harmonik Arus, \% & 11,15 & 14,98 & 8,05 & - \\
10 & Harmonik Tegangan, \% & 2,48 & 2,36 & 2,15 & - \\
\hline
\end{tabular}

\section{a. Tegangan Fasa}

Nilai tegangan hasil pengukuran di BLPT Yogyakarta yang diukur pada panel MDP secara grafik di tunjukkan pada Gambar 2 dan ditabulasikan seperti ditunjukkan pada Tabel 2. 


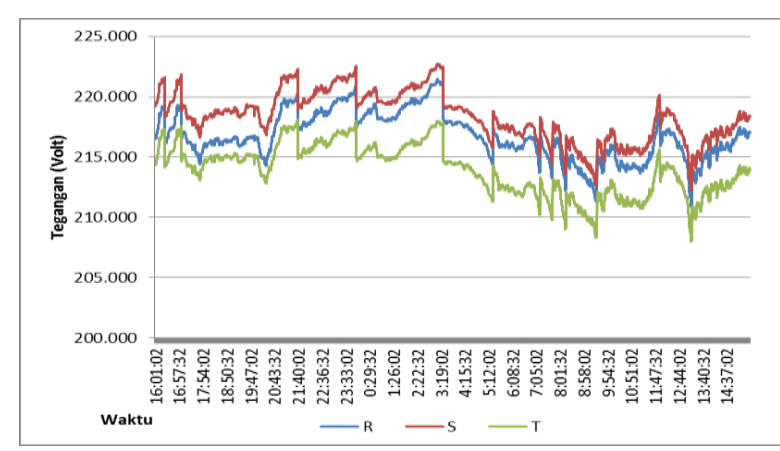

Gambar 3. Profil Tegangan Fasa pada Panel MDP BLPT Yogyakarta

Tabel 2. Nilai Tegangan Fase pada Panel MDP

\begin{tabular}{lccc}
\hline $\begin{array}{c}\text { Nilai } \\
\text { Tegangan }\end{array}$ & $\begin{array}{c}\mathbf{V}_{\text {R-N }} \\
(\text { Volt })\end{array}$ & $\begin{array}{c}\mathbf{V}_{\text {S-N }} \\
(\text { Volt })\end{array}$ & $\begin{array}{c}\mathbf{V}_{\text {T-N }} \\
(\text { Volt })\end{array}$ \\
\hline Minimum & 210,93 & 212,21 & 207,97 \\
Rata-rata & 216,74 & 218,35 & 213,95 \\
Maksimum & 221,47 & 222,76 & 218,13 \\
\hline
\end{tabular}

Berdasarkan Tabel 2 di atas, nilai tegangan fasa pada setiap fasa berbeda yang menyebabkan muncul nilai unbalance voltage. Hasil perhitungan, nilai unbalance voltage rata-rata pada panel MDP sebesar $0,92 \%$, nilai ini belum melebihi batas standar yang ditetapkan oleh NEMA yaitu $1 \%$. Akan tetapi pada kondisi beban tertentu dimana nilai tegangan di panel tersebut turun (nilai terendah) maka nilai unbalance voltage telah melebihi nilai standar yang telah ditetapkan. Tegangan tidak seimbang mengakibatkan terjadinya losses (rugi daya) serta berakibat juga pada pengurangan usia pakai dari peralatan 3 fasa yang terhubung pada sistem.

\section{b. Arus Fasa}

Nilai arus hasil pengukuran di BLPT Yogyakarta yang diukur pada panel MDP secara grafik di tunjukkan pada Gambar 4 dan ditabulasikan seperti ditunjukkan pada Tabel 3.

Tabel 3. Nilai Arus Fase Pada Panel MDP

\begin{tabular}{lcrrr}
\hline \multirow{2}{*}{ Arus Fasa } & $\begin{array}{c}\text { Fasa } \\
\text { R }\end{array}$ & $\begin{array}{c}\text { Fasa } \\
\text { S }\end{array}$ & \multicolumn{1}{c}{ Fasa } & \multicolumn{1}{c}{ Trus } \\
Netral \\
\hline Minimum & 24,66 & 18,81 & 46,75 & 13,71 \\
Rata-rata & 73,73 & 73,27 & 105,77 & 32,36 \\
Maksimum & 177,83 & 203,40 & 227,37 & 103,05 \\
\hline
\end{tabular}

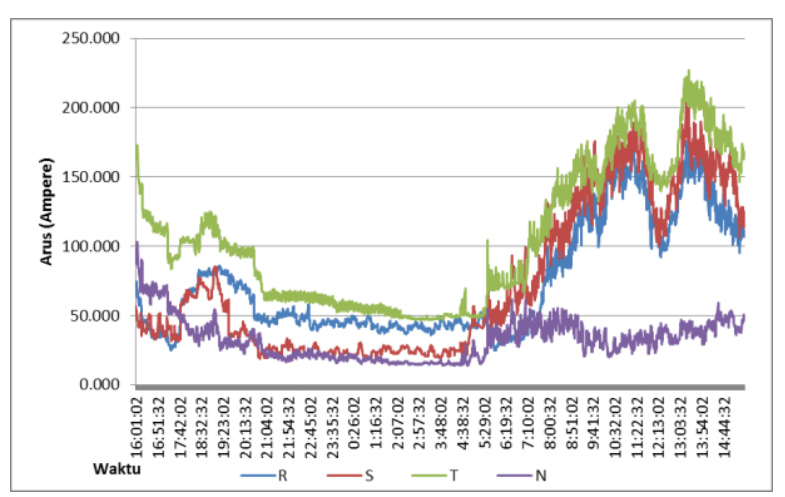

Gambar 4. Profil Arus pada Panel MDP BLPT Yogyakarta

Nilai arus yang ditunjukkan pada Tabel 3 menunjukkan bahwa pada kondisi rata-rata, ada perbedaan arus pada setiap fasa sebesar $25,53 \%$, artinya kondisi pembebanan yang terjadi di BLPT Yogyakarta sudah tidak seimbang dan melebihi batas aman. Batas standard ketidakseimbangan arus beban yang ditentukan oleh NEMA adalah 10\%. Berdasarkan kondisi tersebut, arus yang mengalir di kawat netral sebesar 103,05 ampere (pada kondisi maksimal) perlu diperbaiki guna meminimalisir aliran arus yang terjadi di kawat netral dan menurunkan losses trafo yang diakibatkan oleh aliran arus netral.

\section{c. Daya Semu}

Nilai daya semu (VA) hasil pengukuran di BLPT Yogyakarta yang diukur pada panel MDP secara grafik ditunjukkan pada Gambar 5 dan ditabulasikan seperti ditunjukkan pada Tabel 4.

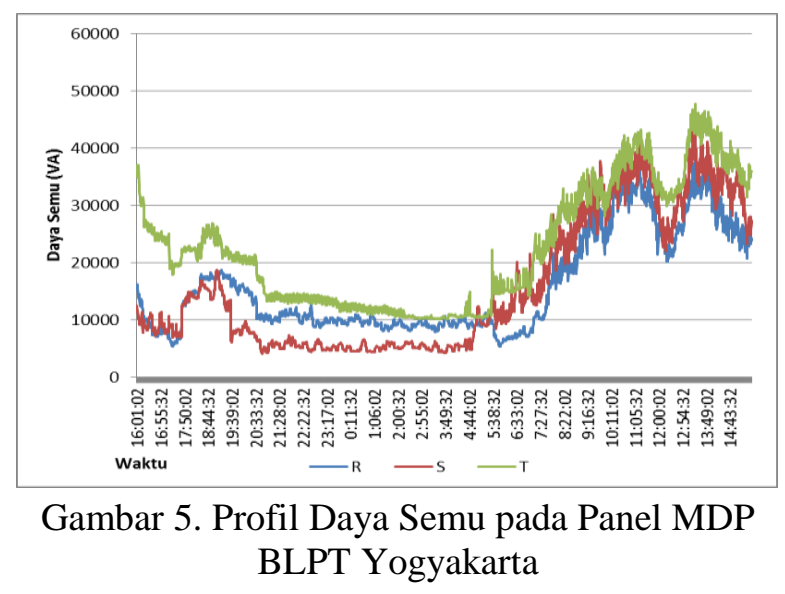


Tabel 4. Nilai Daya Semu pada Panel MDP

\begin{tabular}{lrrl}
\hline $\begin{array}{l}\text { Daya } \\
\text { Semu }\end{array}$ & \multicolumn{1}{l}{ Fasa R } & \multicolumn{1}{l}{ Fasa S } & Fasa T \\
\hline Minimum & $5.332,36$ & $4.137,55$ & $10.079,73$ \\
Rata-rata & $15.927,55$ & $15.913,21$ & $22.561,11$ \\
Maksimum & $37.840,64$ & $43.697,73$ & $47.704,09$ \\
\hline
\end{tabular}

Nilai daya semu yang ditunjukkan pada Tabel 4, menunjukkan bahwa pada kondisi beban rata-rata, ada perbedaan pembebanan pada setiap fasa sebesar $24,41 \%$ pada MDP transformator, artinya kondisi pembebanan yang terjadi di panel relatif tidak seimbang.

Berdasarkan hasil pengukuran nilai daya semu pada kondisi maksimal adalah sebesar 129.242,45 VA atau 129,24 kVA, maka pembebanan pada trafo terpasang $(250 \mathrm{kVA})$ sebesar $51,70 \%$.

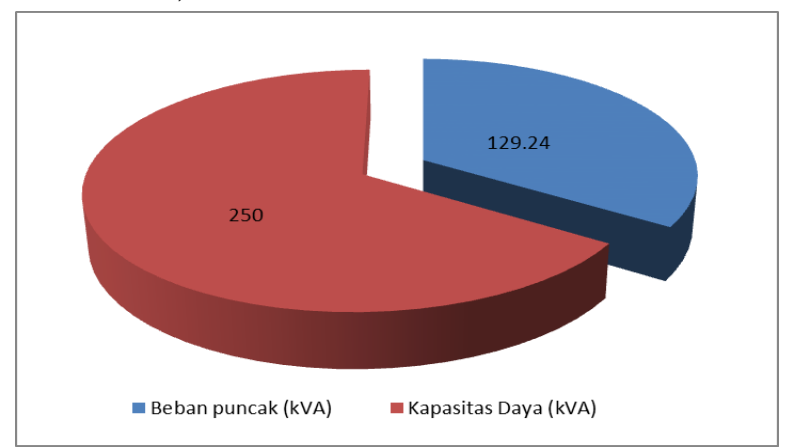

Gambar 6. Perbadingan Kapasitas Daya

\section{d. Daya Nyata}

Nilai daya nyata (watt) hasil pengukuran di BLPT Yogyakarta yang diukur pada panel MDP secara grafik di tunjukkan pada Gambar 7 dan ditabulasikan seperti ditunjukkan pada Tabel 5

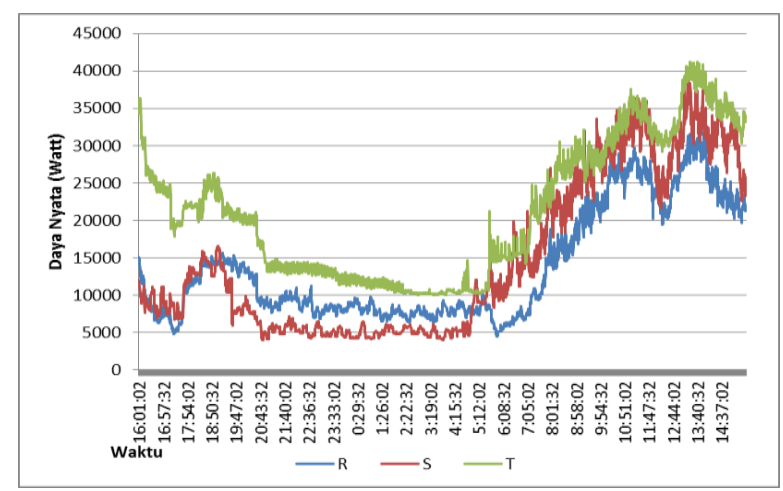

Gambar 7. Profil Daya Nyata pada Panel MDP BLPT Yogyakarta
Tabel 5. Nilai Daya Nyata pada Panel MDP

\begin{tabular}{lrrr}
\hline $\begin{array}{l}\text { Daya } \\
\text { Nyata }\end{array}$ & \multicolumn{1}{l}{ Fasa R } & \multicolumn{1}{l}{ Fasa S } & \multicolumn{1}{l}{ Fasa T } \\
\hline Minimum & $4.467,27$ & $3.974,46$ & $9.976,91$ \\
Rata-rata & $13.754,76$ & $14.905,23$ & $21.331,35$ \\
Maksimum & $31.887,82$ & $39.173,73$ & $41.226,55$ \\
\hline
\end{tabular}

Nilai daya nyata yang ditunjukkan pada Tabel 5 menunjukkan bahwa pada kondisi beban rata-rata, terdapat perbedaan konsumsi daya nyata di setiap fasanya, dengan persentase perbedaan 28,01\% pada panel MDP. Kondisi ini mengakibatkan munculnya arus pada kawat netral yang menyebabkan terjadinya losses pada transformator.

\section{e. Daya Reaktif}

Nilai daya reaktif (VAr) hasil pengukuran di BLPT Yogyakarta yang diukur pada panel MDP secara grafik ditunjukkan pada Gambar 8 dan ditabulasikan seperti ditunjukkan pada Tabel 6

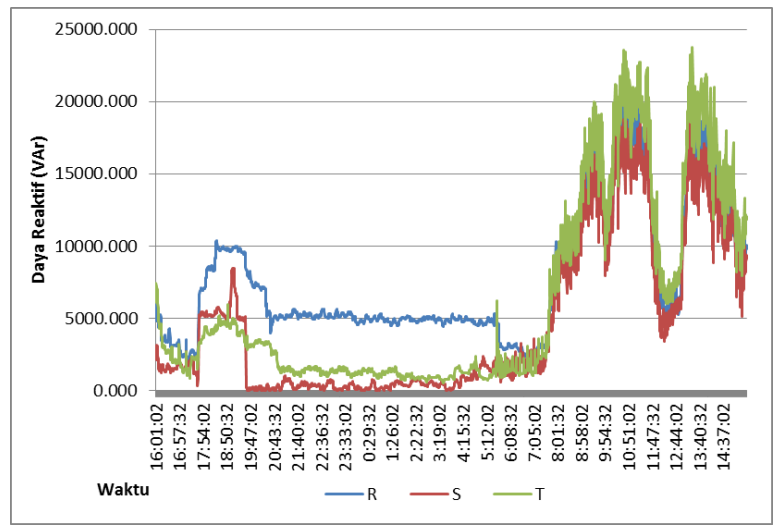

Gambar 8. Profil Daya Reaktif pada Panel MDP BLPT Yogyakarta

Tabel 6. Nilai Daya Reaktif pada Panel MDP

\begin{tabular}{lrrr}
\hline $\begin{array}{l}\text { Daya } \\
\text { Nyata }\end{array}$ & \multicolumn{1}{c}{ Fasa R } & \multicolumn{1}{c}{ Fasa S } & \multicolumn{1}{l}{ Fasa T } \\
\hline Minimum & $1.879,09$ & 0,00 & 546,00 \\
Rata-rata & $7.675,17$ & $4.734,17$ & $6.096,47$ \\
Maksimum & $21.535,09$ & $19.184,46$ & $23.754,55$ \\
\hline
\end{tabular}

Berdasarkan grafik hasil pengukuran terlihat bahwa pada fasa $\mathrm{R}$ konsumsi daya reaktifnya paling tinggi dibandingkan fasa $S$ dan fasa T. Semakin besar konsumsi daya reaktif 
maka akan mengakibatkan losses jaringan yang semakin besar.

\section{f. Faktor Daya}

Nilai faktor daya hasil pengukuran di BLPT Yogyakarta yang diukur pada panel MDP secara grafik ditunjukkan pada Gambar 9 dan ditabulasikan seperti ditunjukkan pada Tabel 7

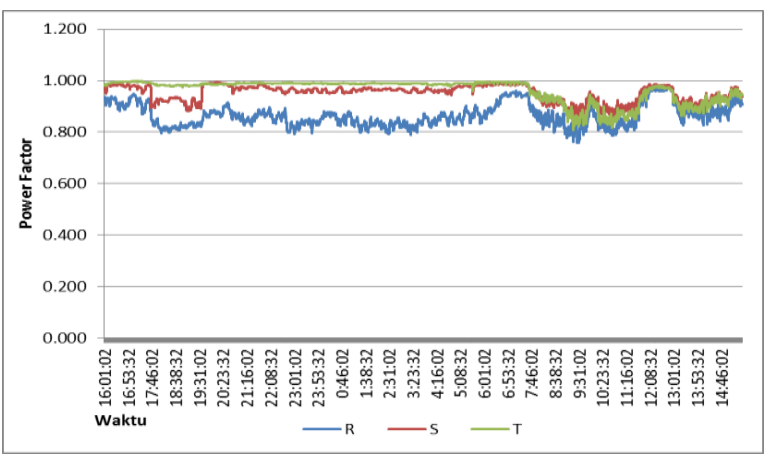

Gambar 9. Profil Faktor Daya pada Panel MDP BLPT Yogyakarta

Tabel 7. Nilai Faktor Daya pada Panel MDP

\begin{tabular}{lrrr}
\hline Faktor Daya (PF) & Fasa R & Fasa S & Fasa T \\
\hline Minimum & 0,76 & 0,85 & 0,81 \\
Rata-rata & 0,86 & 0,95 & 0,96 \\
Maksimum & 0,98 & 0,99 & 1,00 \\
\hline
\end{tabular}

Nilai faktor daya yang ditunjukkan pada Tabel 7 menunjukkan bahwa secara umum pada kondisi rerata nilai faktor daya masing-masing fasa pada panel MDP sudah sesuai dengan standar yang telah ditetapkan oleh PLN yaitu lebih besar atau sama dengan 0,85 . Nilai faktor daya yang rendah akan mengakibatkan konsumsi daya reaktif sangat besar sehingga berakibat pada kenaikan rugi daya (losses) secara keseluruhan.

\section{g. THD Tegangan}

Nilai THD Tegangan hasil pengukuran di BLPT Yogyakarta yang diukur pada panel MDP secara grafik ditunjukkan pada Gambar 10 dan ditabulasikan seperti ditunjukkan pada Tabel 8

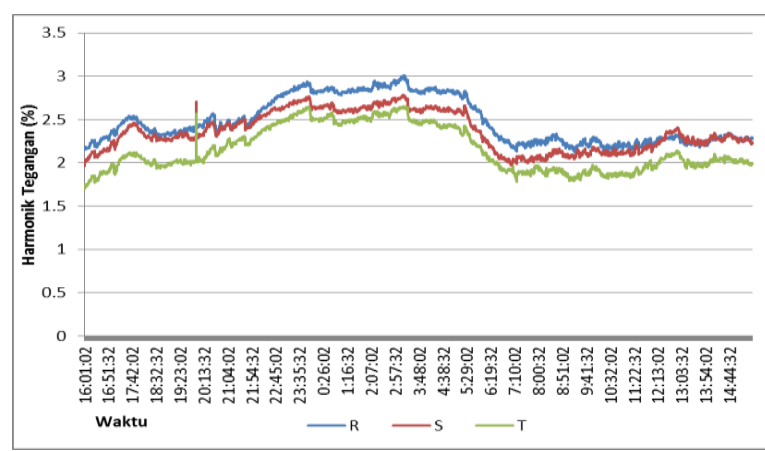

Gambar 10. Profil THD Tegangan pada Panel MDP BLPT Yogyakarta

Tabel 8. Nilai THD Tegangan pada Panel MDP

\begin{tabular}{lrrr}
\hline THD Tegangan & \multicolumn{1}{c}{ Fasa $\mathbf{R}$} & \multicolumn{1}{c}{ Fasa $\mathbf{S}$} & \multicolumn{1}{c}{ Fasa T } \\
\hline Minimum & 2,12 & 1,96 & 1,69 \\
Rata-rata & 2,48 & 2,36 & 2,15 \\
Maksimum & 3,01 & 2,78 & 2,66 \\
\hline
\end{tabular}

Nilai THD tegangan rata-rata pada panel MDP berkisar antara 1,69 hingga 3,01 persen Dengan mengacu ke standar IEEE 519-1992, nilai THD tegangan untuk tegangan dibawah 69 $\mathrm{kV}$ yaitu 5 persen, maka nilai THD tegangan rata-rata di panel MDP masih di bawah standard yang telah ditentukan oleh IEEE.

\section{h. THD Arus}

Nilai THD arus hasil pengukuran di BLPT Yogyakarta yang diukur pada panel MDP secara grafik ditunjukkan pada Gambar 11 dan ditabulasikan seperti ditunjukkan pada Tabel 9.

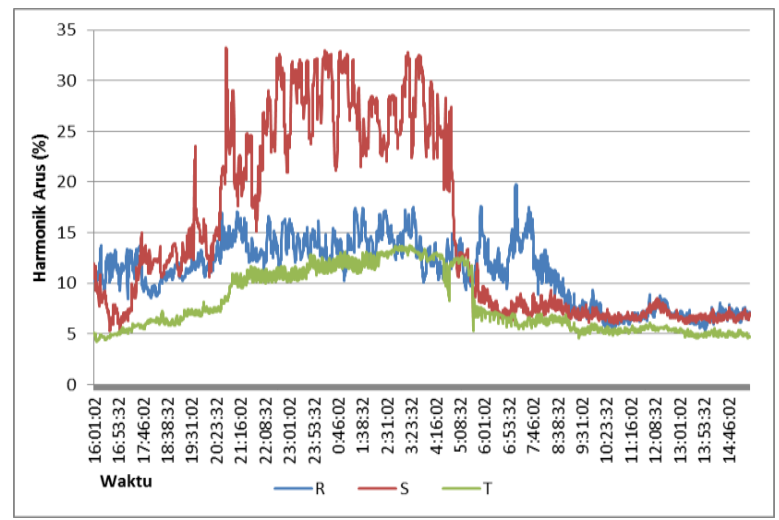

Gambar 11. Profil THD Arus pada Panel MDP BLPT Yogyakarta 
Tabel 9. Nilai THD Arus pada Panel MDP

\begin{tabular}{lrrr}
\hline THD Arus & Fasa R & Fasa S & Fasa T \\
\hline Minimum & 5,33 & 5,23 & 4,22 \\
Rata-rata & 11,15 & 14,98 & 8,05 \\
Maksimum & 19,77 & 33,30 & 13,72 \\
\hline
\end{tabular}

Nilai THD arus rata-rata pada panel MDP berkisar antara 4,22 hingga 33,30 persen. Hal ini mengacu ke standar IEEE 519-1992 (1993), nilai THD arus untuk tegangan dibawah $69 \mathrm{kV}$ yaitu 15 persen, maka nilai THD arus sudah melebihi batas standar yang ditentukan oleh IEEE.

\section{SIMPULAN}

Daya total tersambung dari PT PLN (Persero) yang digunakan di Balai Latihan Pendidikan Teknik (BLPT) Yogyakarta untuk menggerakkan peralatan utama utilitas, peralatan utama proses dan kebutuhan perkantoran adalah 1.495 kVA yang terbagi dalam dua titik langganan yaitu $345 \mathrm{kVA}$ dan $1.150 \mathrm{kVA}$. Berdasarkan hasil pengukuran, beban puncak di Balai Latihan Pendidikan Teknik (BLPT) Yogyakarta adalah 384.299,73 VA. Berdasarkan hasil pengukuran dan analisis yang telah dilakukan kondisi yang paling menonjol adalah adanya indikasi aliran arus di kawat netral yang cukup tinggi, yaitu 103,05 ampere dimana nilai tersebut akan berdampak pada kerugian energi pada saluran netral maupun rugi-rugi pada transformator.

\section{DAFTAR RUJUKAN}

BLPT Yogyakarta. 2015. Profil-Visi-misi BLPT DIY. Diakses dari http://www.blptjogja.or.id, 30 September 2019

Dugan, R.C., McGranaghan, M. F., and Beaty, H. W. 1996. Electrical Power Sistems Quality. New York: McGraw-Hill.

IEEE Std 519-1992. 1993. IEEE Recommended Practices and Reqirements for Harmonic Control in Electrical Power System. IEEE: NewYork,

Stamenić, M., Jankes, G., Tanasić, N., Trninić, M., \& Simonović, T. 2012. Energi Audit as a Tool for Improving Overal Energi Efficiency in Serbian Industrial Sector. 2nd International Symposium on EnvironmentFriendly Energies and Applications (EFEA).

PT. PLN Persero. 2018. Statistik PLN. Sekretariat Perusahaan PT. PLN (Persero). 